\title{
The Dynamics of Decision Making in Penalty Kick Situations in Associa- tion Football
}

\author{
J.E. Lopes ${ }^{1}$, D. Araújo**1, R. Peres ${ }^{2}$, K. Davids ${ }^{3}$ and J. Barreiros ${ }^{1}$ \\ ${ }^{1}$ Faculty of Human Kinetics, Technical University of Lisbon, Portugal; ${ }^{2}$ Sporting Clube de Portugal, Portugal; \\ ${ }^{3}$ Queensland University of Technology, Australia
}

\begin{abstract}
This paper reviews research on decision-making behavior of both goalkeeper and penalty taker during penalty kick situations in association football. Specifically, it adopts an ecological dynamics perspective on the behavior of both penalty taker and goalkeeper exemplifying how each might constrain the other's decisions. This conceptual framework is elucidated to suggest key ideas for designing experimental programs on the penalty kick. We conclude by discussing the implications of ecological dynamics to advance research and practice in the penalty kick.
\end{abstract}

\section{INTRODUCTION}

A penalty kick in association football takes less than 2 seconds, and yet it is a moment of rare emotional intensity, especially for both players directly involved. In this task both players face unavoidable task constraints imposed by the laws of the game ${ }^{1}$. Rules and physical constraints place the penalty kick as a significant, categorical event, i.e. with outcomes of "goal" or "no goal" and no possible intermediate levels of performance. Statistically, the relative importance of a penalty kick increases within a series (such as during a penalty shoot out), and failure becomes more influential to the final outcome [1]. Although strategic planning for competition could be based on a consideration of players' skills in converting penalty kicks, surprisingly this is not commonly adopted in professional football [1]. Perhaps more surprisingly, penalty taking does not typically play a major role in training programs. Social constraints also have a significant influence in the successful outcome of the event, with strong pre-conceptions biased towards kicker success and goalkeeper failure influencing the players' performance. In this paper, we argue that, due to the broad range of constraints influencing the behavior of both players involved in the penalty kick, a better understanding of this performance context might be achieved through adopting a multifaceted performance assessment (i.e. perceptual-cognitive and biomechanical measurement approaches). The result could be an improvement of the representative design of experiments from social, cognitive, energetic and biomechanical

*Address correspondence to this author at the Faculty of Human Kinetics, Technical University of Lisbon, Portugal; Tel: +351214149209; Fax: +351214144712; E-mail: daraujo@fmh.utl.pt

\footnotetext{
${ }^{1}$ The rules include: (i) the obligation for the goalkeeper to keep his/her feet on the goal-line, with no possibility to move towards the ball (reducing the possible available angle for the kicker) until the ball has been kicked; (ii) the lack of a defensive barrier for the goalkeeper, which is a rules-based exclusive characteristic of the penalty kick, compared to direct or indirect free kicks; (iii) the short distance to the goal $(11 \mathrm{~m})$ from the penalty spot; (iv) the infeasibility of the kicker completely stopping his/her approach to the ball after starting the run up.
}

perspectives. This multi-disciplinary emphasis has implications for training and experimental task designs achieved by focusing on the adaptive behaviors of both players, which emerge from the dynamics of their interpersonal interactions during performance under several types of constraints.

\section{INSIGHTS FROM RECENT RESEARCH ON THE PENALTY KICK}

In recent years, there have been numerous attempts to study performance in the penalty kick situation [1-5], with good agreement over the percentage of missed penalty kicks (25-30\%) reported. Research by Van der Kamp [from 4], reported differences of around $30 \%$ between successful and unsuccessful goalkeepers, at an expert level. We can derive three important conclusions from the extant data: (i) to score from the penalty kick spot is a demanding task that requires the development of a specific skill to be successful; (ii), the goalkeeper plays a significant role in the final outcome of this particular event; and (iii) the behavior of the penalty kicker and the goalkeeper become coordinated in a specific interaction.

Existing research on penalty kicking (see Table 1) can be divided into different bodies of work. For example, some descriptive studies have examined the influence of probabilistic tactical models on the final outcome with respect to the positioning of penalty kickers and goalkeepers in a penalty kick shoot-out [1]. For example, some work [3] has shown how variations in off-centre standing positions of goalkeepers, in the order of 6-9 cms, can influence the success of penalty kicks. Other studies have been based on data collected from association football competitions, illustrating the influence of individual constraints (e.g., stress, skill and fatigue) on the final outcome of the penalty shoot out phase [2]. An additional body of work has examined visual search patterns and anticipation of goalkeepers, when watching penalty kick film clips [4,6-8], with particular emphasis on ascertaining point-of-gaze data. There have also been investigations of performance differences when goalkeepers are confronted with right- and left-footed penalty takers [9]. 
In the main these studies have revealed some common conclusions, including the following: (i) hips and the nonkicking leg of penalty takers seem to be relevant sources of information for anticipation of the kick direction by goalkeepers; (ii) penalty takers cannot alter kick direction without performance decrements when a goalkeeper moves between $400 \mathrm{~ms}$ to $300 \mathrm{~ms}$ prior to foot-ball contact $[5,10]$; (iii) successful goalkeepers wait longer to initiate actions [6,4]; (iv) goalkeepers can influence the 'faux perception' of a goal's area and consequently the direction of penalty kicks [from 11 in related work on facing a penalty throw in handball; see also [3]]; (v) there is a strong association between the importance of a kick for a match's result and effective performance [1,2]; and (vi), there is an association between

Table 1. A Summary of the Key Studies on Penalty Kick (PK) Situations in Soccer

\begin{tabular}{|c|c|c|c|c|}
\hline Authors (Year) & Participants & Research Design & Laboratory Test & Basic Findings \\
\hline $\begin{array}{l}\text { Morris \& Burwitz } \\
\qquad(1989)\end{array}$ & $\begin{array}{l}\text { Professional Goal- } \\
\text { keepers (GKs) }\end{array}$ & $\begin{array}{l}\text { Analysis of GKs' anticipation move- } \\
\text { ments, based on keeper-dependence and } \\
\text { independence strategy of the kickers }\end{array}$ & $\begin{array}{l}\text { Recording of physical } \\
\text { actions in dynamic on- } \\
\text { court situations; } a \text { priori } \\
\text { response questionnaire }\end{array}$ & $\begin{array}{l}\text { GKs were able to anticipate } \\
\text { PKs above chance levels; }\end{array}$ \\
\hline $\begin{array}{l}\text { Williams \& Bur- } \\
\text { witz (1993) }\end{array}$ & $\begin{array}{l}\text { Amateur and semi- } \\
\text { prof. GKs }\end{array}$ & $\begin{array}{l}\text { Anticipation of PK's direction by con- } \\
\text { straining time and visual info. }\end{array}$ & $\begin{array}{l}\text { Film-based occlusion test; } \\
\text { pen and paper response }\end{array}$ & $\begin{array}{l}\text { Hips as main source of infor- } \\
\text { mation in PK's direction }\end{array}$ \\
\hline $\begin{array}{l}\text { McMorris \& Col- } \\
\quad \text { enso (1996) }\end{array}$ & Professional GKs & $\begin{array}{c}\text { Anticipation of PK's direction, by con- } \\
\text { straining time, visual information and } \\
\text { angle of approach }\end{array}$ & $\begin{array}{l}\text { Film-based occlusion test; } \\
\text { post-hoc interview }\end{array}$ & $\begin{array}{l}\text { Angle of approach, foot and } \\
\text { hip position, are cues to antici- } \\
\text { pation }\end{array}$ \\
\hline $\begin{array}{l}\text { McGarry \& Franks } \\
\qquad(2000)\end{array}$ & Data of PKs shoot-out & $\begin{array}{l}\text { Probabilistic analysis of line-up order, } \\
\text { regarding: possible outcomes, stress level }\end{array}$ & $\begin{array}{l}\text { On-court assessment via } \\
\text { video analysis; computer } \\
\text { simulation }\end{array}$ & $\begin{array}{l}\uparrow \text { efficacy when alignment by } \\
\text { reverse order of players' ability } \\
\text { in PK's shoot-out situation }\end{array}$ \\
\hline Morya et al. (2003) & $\begin{array}{l}\text { University soccer } \\
\text { players }\end{array}$ & $\begin{array}{l}\text { Keeper-dependence and independence } \\
\text { strategy dynamical analysis }\end{array}$ & $\begin{array}{l}\text { Joystick response; visual } \\
\text { gaze record }\end{array}$ & $\begin{array}{l}\text { Time to commitment of GKs } \\
\text { for one side leads to variations } \\
\text { in kickers' performances }\end{array}$ \\
\hline $\begin{array}{l}\text { Savelsbergh et al. } \\
\qquad(2002)\end{array}$ & $\begin{array}{l}\text { Expert and novices } \\
\text { GKs }\end{array}$ & $\begin{array}{c}\text { Differences in anticipation measures } \\
\text { of PK's direction and visual search be- } \\
\text { havior }\end{array}$ & $\begin{array}{l}\text { Film-based anticipation } \\
\text { test; joystick response; } \\
\text { gaze record }\end{array}$ & $\begin{array}{l}\text { Expert GKs were more accu- } \\
\text { rate, waited longer before re- } \\
\text { sponse initiation, made fewer } \\
\text { corrections }\end{array}$ \\
\hline $\begin{array}{l}\text { Savelsbergh et al. } \\
\qquad(2005)\end{array}$ & $\begin{array}{l}\text { Prof. and semi- } \\
\text { Professional GKs }\end{array}$ & $\begin{array}{c}\text { Differences in anticipation measures of } \\
\text { PK's direction and visual search behavior }\end{array}$ & $\begin{array}{l}\text { Film-based anticipation } \\
\text { test; joystick response; } \\
\text { visual gaze record }\end{array}$ & $\begin{array}{l}\text { Successful GKs predict better } \\
\text { height and direction of PK. } \\
\text { Waited longer time to respond }\end{array}$ \\
\hline Poulter et al. (2005) & $\begin{array}{l}\text { University students } \\
\text { (no experience) }\end{array}$ & $\begin{array}{l}\text { Effect of instructional condition (explicit } \\
\text { and implicit) on point-of-gaze, regarding } \\
\text { anticipation of kick's direction }\end{array}$ & $\begin{array}{l}\text { Film-based occlusion test; } \\
\text { pen and paper response; } \\
\text { visual gaze record }\end{array}$ & $\begin{array}{l}\text { Explicit learning results in } \\
\text { changes in gaze behaviour and } \\
\text { increased awareness. }\end{array}$ \\
\hline $\begin{array}{l}\text { Van der Kamp } \\
(2006)\end{array}$ & $\begin{array}{l}\text { University soccer } \\
\text { players }\end{array}$ & $\begin{array}{l}\text { Kicker dependence or independence } \\
\text { relatively to GK's actions }\end{array}$ & $\begin{array}{l}\text { Recording of physical } \\
\text { actions in dynamic on- } \\
\text { court situations; }\end{array}$ & $\begin{array}{l}\text { Worse performance in GK- } \\
\text { dependent strategy. }\end{array}$ \\
\hline Bakker et al. (2006) & $\begin{array}{c}\text { Amateur soccer play- } \\
\text { ers }\end{array}$ & $\begin{array}{c}\text { Manipulation of kickers' intentions by } \\
\text { changes in gaze behavior under time } \\
\text { constraints }\end{array}$ & $\begin{array}{l}\text { Recording of physical } \\
\text { action in dynamic film- } \\
\text { based situation; gaze } \\
\text { behavior rec. }\end{array}$ & $\begin{array}{l}\text { Negative instructions related } \\
\text { with PK's unwanted effects, by } \\
\text { changes in gaze behavior }\end{array}$ \\
\hline $\begin{array}{l}\text { Bar-Eli et al. } \\
\qquad(2007)\end{array}$ & $\begin{array}{l}\text { Data of PKs from top } \\
\text { Leagues worldwide }\end{array}$ & $\begin{array}{l}\text { Probabilistic analysis of stopping PKs } \\
\text { based on: jumps sides, kicks directions } \\
\text { and GKs opinion About normal behav- } \\
\text { iour when stopping PKs }\end{array}$ & $\begin{array}{l}\text { On-court assessment via } \\
\text { video analysis; inferential } \\
\text { data analysis; question- } \\
\text { naire }\end{array}$ & $\begin{array}{l}\text { Optimal strategy for GKs is to } \\
\text { stay in the goal's centre (inac- } \\
\text { tion); }\end{array}$ \\
\hline Jordet et al. (2007) & PKs shoot-out data & $\begin{array}{l}\text { Statistical relation between PK's out- } \\
\text { come and: role, playing time, age, PK's } \\
\text { number, competition }\end{array}$ & $\begin{array}{l}\text { On-court assessment via } \\
\text { video analysis; inferential } \\
\text { data analysis }\end{array}$ & $\begin{array}{l}\text { Psychological variables } \\
\text { strongly related with outcome }\end{array}$ \\
\hline $\begin{array}{l}\text { Masters et al. } \\
\qquad(2007)\end{array}$ & $\begin{array}{l}\text { Unspecified partici- } \\
\text { pants }\end{array}$ & $\begin{array}{l}\text { Manipulation of informational con- } \\
\text { straints, (GK's body-scaled metrics and } \\
\text { goal's area perception) }\end{array}$ & $\begin{array}{l}\text { Slide recognition test; } \\
\text { simulated field-based } \\
\text { recognition test; verbal } \\
\text { response }\end{array}$ & $\begin{array}{l}\text { Feasibility for GK to influence } \\
\text { kick's direction, by influencing } \\
\text { kicker's perception of goal area }\end{array}$ \\
\hline $\begin{array}{l}\text { Van der Kamp \& } \\
\text { Masters (in press) }\end{array}$ & $\begin{array}{l}\text { Undergraduate stu- } \\
\text { dents }\end{array}$ & $\begin{array}{c}\text { Biased perception of GK's size (illusion), } \\
\text { which may affect kicker's visual infor- } \\
\text { mation }\end{array}$ & $\begin{array}{l}\text { Photo recognition test; } \\
\text { simulated field-based } \\
\text { recognition test; pen and } \\
\quad \text { paper response; }\end{array}$ & $\begin{array}{l}\text { GK posture affects perception } \\
\text { of GK's height which has in- } \\
\text { fluence on PK's accuracy }\end{array}$ \\
\hline
\end{tabular}


negatively phrased instructions by the coach and performance of the penalty kick [12].

It is worth noting that the major proportion of studies on this topic have been conducted from the penalty taker's point of view $[3,5,10,12]$. Only a few investigations have tried to analyze the goalkeeper's behavior and performance. Of those latter studies, a striking finding is that the probability of success seems to increase if a goalkeeper uses "advanced postural cues" from the kicker to decide on the spatial location of the kick and dives at the precise moment when a penalty taker can no longer modify the ball's trajectory $[4,6,13]$, as reported in Table $\mathbf{1}$.

Some research $[4,5,10]$ has suggested a link between the action of the goalkeeper and the penalty taker (e.g. when goalkeepers wait longer before diving, the penalty taker assumes a 'keeper-dependent strategy' ${ }^{2}$ ). This is an important observation since this coupling link could be taken to imply that both participants function as a dyadic system during performance. Elsewhere, we have theoretically modeled dyadic systems in sport, exemplified by $1 \mathrm{v} 1$ sub-phases of team games, in which immediate opponents are directly engaged in interpersonal interactions (i.e. due to their coinfluences, their actions and decisions cannot be considered independently of each other) (for research in boxing, basketball and rugby union see [14-16]. However, in some circumstances, e.g., when the goalkeeper decides early which way to dive or when the penalty taker decides beforehand which side to shoot at (adopting a keeper-independent strategy), the reciprocal influence between these players remains unclear. We will return to this theoretical work later in this paper.

\section{EXPERIMENTAL DESIGNS IN THE PENALTY KICK SITUATION}

It could be argued that much of the research on the penalty kick in association football has lacked representative experimental design. According to Araújo, Davids and Passos [17], the concept of "representative experimental design", initiated by Brunswik [18], refers to the set up of an experiment so that it represents the behavioral (performance) context to which results are intended to apply. Following Gibson [19], Araújo et al. [17] argued that experimental tasks should be set up in such a way that the actors involved can perceive in order to act, but also can act in order to perceive. From this standpoint, a major criticism of extant experimental designs in penalty kicking research has been the lack of opportunity to examine the reciprocal interaction between the penalty taker and goalkeeper from a perceptionaction coupling perspective.

To exemplify, important limitations of previous investigations have included the following: (i) a restricted measurement approach to measuring performance in the penalty kick; (ii) the tendency to adopt a static (snap-shot) evaluation of decision making of both the goalkeeper and the penalty taker; and (iii) the use of non task-specific methods for measuring the response modes of participants in research

\footnotetext{
${ }^{2}$ A keeper-dependent strategy is one in which the kicker attempts to orient the direction of the kick based on the direction of the movement of the goalkeeper. In contrast a keeper-independent strategy is one in which the kicker orients the direction of the kick, regardless of the goalkeeper's movement direction.
}

studies. For example, Savelsbergh et al. [4,6], like McMorris and Colenso [9] studied the visual search behavior of goalkeepers by asking them to merely observe film clips of penalty kicks. From those data, it is unclear how the identified visual search behaviors of the goalkeepers relate to their actions when attempting to save a penalty kick. In another example, Morya et al. [10] used a computer simulation of a penalty kick, where both performers were represented by two white disks, and where the goalkeeper's movements were computationally determined, thus involving no influence of the kicker's actions. In others works, Masters et al. [3] or Van der Kamp and Masters [11] used static images of the goals and Van der Kamp [5], measured the consequences of late alterations (by the penalty taker) in the direction of the penalty kick, by replacing the goalkeeper's movements with a series of flashing lights. Although there have been meritable contributions to knowledge from all these studies, their primary limitations are based on the failure to conceptualise and study the penalty kick performance context as a dyadic system to observe dynamics of penalty kicker-goalkeeper interactions. This criticism suggests some caution in generalizing the extant data to understanding performance of penalty kicks during an actual game.

The link between perception and action in the penalty kick is underpinned by both goalkeepers and penalty takers probably tending to disguise their actions in an attempt to confound an opponent's perception. Because of that, and in relation to gaze behavior in controlled experimental environments, Bakker et al., [12] argued that in the task of the penalty kick in association football, less appropriate (e.g. the goalkeeper, or outside the goal) and more appropriate (i.e. the open goal space) gaze locations can be distinguished. Another important feature is the extant data on movement outcome variability suggesting that performers find the task constraints of actual interceptive actions in sport more functionally relevant than experimental ones [15]. The implications of these conclusions to experimental designs in the penalty kick, suggest that the manipulation of objects such as joysticks or keyboards with measurable outputs representing the performances of kickers or goalkeepers, should be eschewed for the unique interpersonal interactions performed in such sports tasks. Clearly the number of variables that might constrain the penalty task is so wide that experimental work was probably pushed towards oversimplified experimental designs. This is a common observation in scientific sub-disciplines that have to deal with highly complex interactions. One reason for this is the absence of theoretical models to integrate and interpret the interactions of all the related variables. In this line of thought, experimental designs in the penalty kick situation could consider identifying and quantifying the influence of performers' movement strategies in all outcomes. These changes in methodology would benefit from the implementation of a theoretical framework that could explain: (i) why expert association football goalkeepers wait longer to initiate their actions [4], which is related to reduced accuracy of the penalty taker when information about the goalkeeper's dive is detected shortly before ball-foot contact [5]; (ii) why a keeperdependent strategy is particularly advantageous when the goalkeeper commits himself early [5]; and (iii), why goalkeepers may exhibit performance differences when facing 
right- or left-footed penalty takers [9]. Finally, as already proposed by Van der Kamp [5], any attempt to generalize from experiments to actual penalty kick situations, should consider participant's movement strategies in competition. As proposed earlier, such an explanation could emanate from an "ecological dynamics" theoretical framework [14], which uses concepts and tools of dynamical systems to understand phenomena that occur at an ecological scale - the scale where the relationship between the goalkeeper and the penalty taker is established in this specific performance context. Although scientific reductionism has dominated the methods of the first phase of research on the penalty kick, it should be recognized that this step was and still is important to identify relevant constraints on the penalty situation. However, theoretical models are emerging which strongly encourage a systems-oriented approach to examining pattern forming dynamics of the keeper-kicker interactions driven by informational constraints. Within ecological dynamics, Brunswik's representative task design is a key concept to drive research design.

\section{THE ECOLOGICAL DYNAMICS OF THE PENALTY KICK}

In an ecological dynamics interpretation, the relationship between performers in a penalty kick situation can be assumed to possess the characteristics of a dynamical system $[20,21]$. Having many degrees of freedom and several levels, dynamical systems at an ecological scale have three main features worth emphasizing including: (i) non-linearity of behavioral output; (ii) a capacity for stable and unstable patterned relationships between parts of the system (i.e. coordinated states) to emerge through system self-organization; and (iii), the ability of subsystem components to constrain the behavior of other subsystems [22]. These attributes are particularly relevant to the penalty kick if we assume decision-making behavior as emerging from the dynamical interactions of performers (e.g. in competing or cooperative relationships) towards specific goals (i.e. to score or to save a goal), influenced by environmental and individual constraints over time [14]. Following insights of Araújo et al. [14], the aim of the penalty taker may be seen as breaking the stability of the coupled system established between him/her and the goalkeeper. From a macroscopic perspective, all actions of the penalty taker are intended to place the ball away from the goalkeeper's range of action, while the latter is continuously trying to maintain the initial symmetry with the kicker in an attempt to intercept the ball. At this level of analysis, therefore, penalty kicks can be described as the creation, maintenance and dissolution of a "dyad", which relies on information about its ongoing coordinative state. Theoretically, for this dyadic system to be created there should be a continuous coupling between information and action for both players. This spontaneous system is created when a penalty is awarded and a kicker faces a goalkeeper, both waiting for the referee to initiate action. The information-action coupling [23] between participants in the dyad allows prospective control. A prospective control strategy in dyadic sub-systems of team sports means that performers can control their actions based on the ongoing difference between the current behavior and state of the system, and the goal state [24]. Observed differences in these states give rise to adaptations by individuals in the dyad, which in turn mod- ify each performer's current relationship with the environment, in an ongoing cyclical fashion. Information and action are intertwined in the dyadic system control process. Interestingly in the penalty kick situation, these continuous cycles of information-action couplings happen simultaneously for kicker and goalkeeper. Moreover, the information that constrains action should specify the properties of the environment that are relevant for effective action. This is an important methodological point since information-action couplings emerge from representative task designs (actual penalty kicking and goalkeeping), rather than response simulations and stimuli in contrived experiments. As mentioned before, Brunswik [18] suggested an emphasis on experimental designs that specify those conditions toward which a generalization is intended. The essential characteristic of "representative design", as he termed it, is that the experimenter carefully specifies what generalizations can be made from an experiment and then sets it up to examine those generalizations. According to Gibsonian theorising, decision-making is typically based on a continuous and active process of exploration and selection of relevant information to support choices. This means that, actions require that information about environmental constraints be referential to the energy for behaving with respect to those constraints. The implication is that experimental tasks should be designed to ensure correspondence between phenomena of interest (e.g., penalty situation) manifested by the individual both in a performance context and an experimental task [17].

In the association football penalty kick there is the possibility that the kick's direction is defined beforehand by the penalty taker who is trying to disrupt the system's symmetry by focusing on the accuracy of the kick to its pre-defined direction and trying to disguise it from the goalkeeper [5]. Based on ecological dynamics, in some cases, the initial keeper-independent strategy adopted by the penalty kicker can evolve, during the run up, to a keeper-dependent one, due to the goalkeeper's actions. This could occur when a goalkeeper tries to constrain the penalty taker's actions by standing marginally on one side or another of the goal center [3], or when he/she creates a diversion by waving the arms in the air or by moving from side to side across the goal-line with no commitment to one side of the goal.

In sum, from an ecological dynamics approach, it is possible to conceptualize the penalty kick as a dynamical system, where there is a constant search for relevant information to achieve specific competition goals [14], and where competitors can induce the occurrence of interactions between them, and between them and the environment. This approach allows the measurement of the dynamic interactions of relevant variables in the penalty kick, and examines the emergent mutuality of a dyadic social system (goalkeeper and kicker) as unfolding over time [25]. To study the ecological dynamics of the penalty kick, the identification of relevant constraints is required [26]. These include task constraints, like the limited action of the goalkeeper restrained to the goal-line, the distance from the penalty spot to the goal or the goal's dimensions; environmental constraints such as the level of the competition, or weather conditions, and organismic constraints such as the weight and height of the goalkeeper relatively to goal dimensions, the self-perceived strength of the penalty taker when defining the direction and 
Goalkeeper:

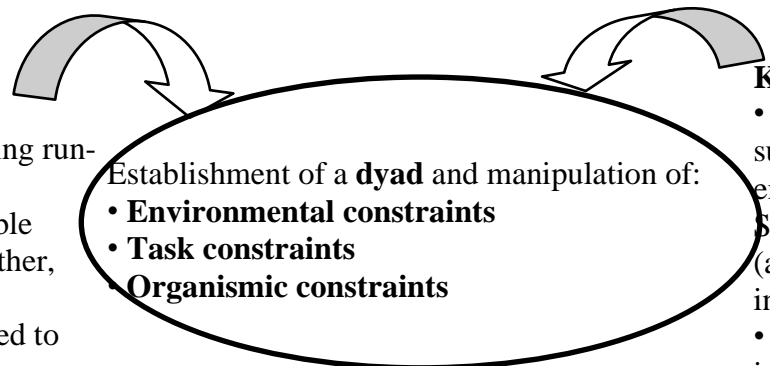

Kicker:

- Immobility/Mobility during runup of kicker;

- Goalkeepers’ imperceptible position to one side or another, relative to goal's center;

- Goalkeepers' gaze directed to specific places of relevant information;

- To create similar emotional variations similar to those experienced by kickers; - To create similar sources of irrelevant information as experienced by kickers;

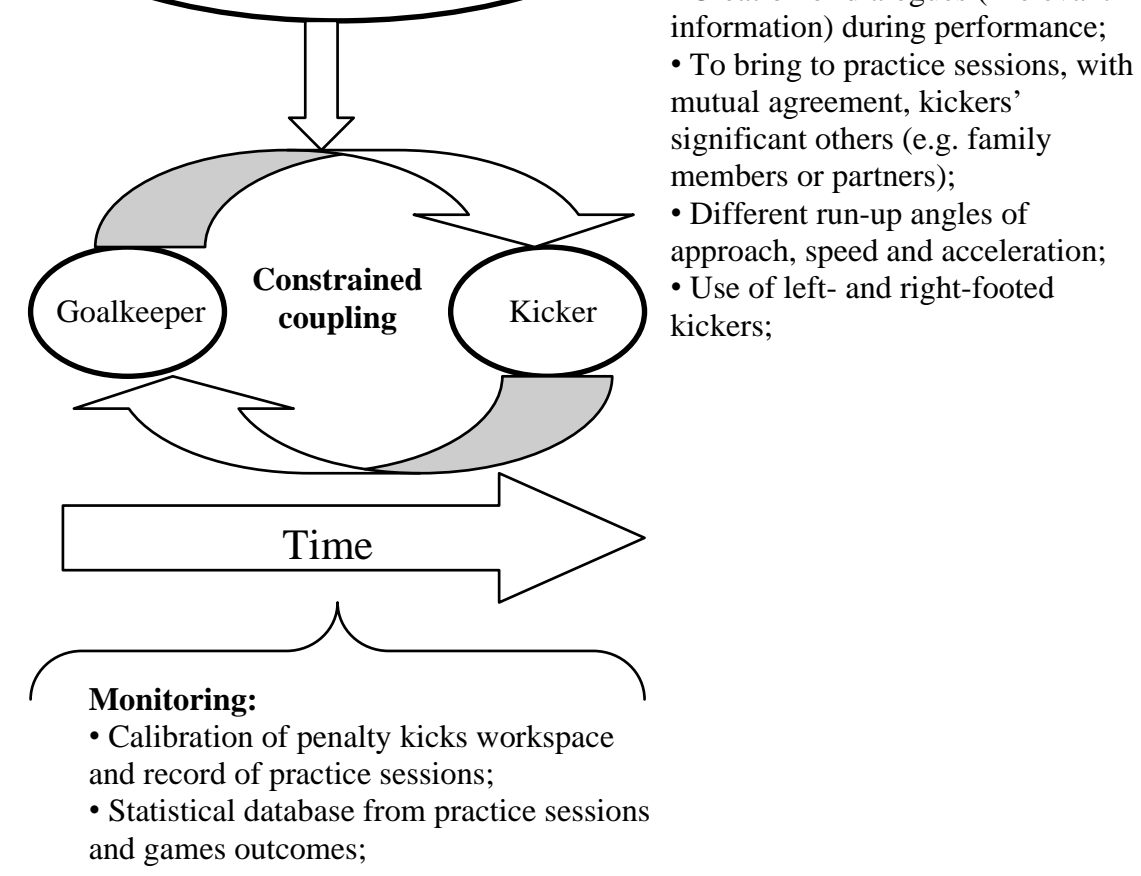

- Changes in kickers' ranking, in such a way that the most emotionally pusceptible kickers shoot the latest and more decisive) penalty kicks in penalty shootout practice; - Creation of dialogues (irrelevant information) during performance; sions, with significant others (e.g. family members or partners); Different run-up angles of (x) (a) and record of practice sessions; and games outcomes;

Fig. (1). Schematic representation of major constraints that could be taken into account in the design of penalty kicks exercises.

velocity of the ball, the strategies employed by both players, and the emotional pressure imposed in specific penalty kicks designs It should be noted, however, that the aim of research is not to measure or control every variable available. Ecological dynamics proposes the identification of candidate control parameters and order parameters that capture system organisation and informational constraints. This modeling can emerge from experiential knowledge as well as theoretical development and empirical research [see 14-16].

\section{NEW CHALLENGES FOR THE DESIGN OF EX- PERIMENTAL AND TRAINING TASKS}

An ecological dynamics perspective on the design of experimental tasks and training programmes raises the following inter-related questions: (i) how do goalkeeper and kicker strategies constrain the dynamics of the dyadic system?; (ii) which variables explain the coupling of each player as an interacting element in the dyadic system?; (iii) how can representative design of experiments and training programmes be enhanced?

Several authors have argued that future experimental task designs should be more representative of performance settings when trying to study the reciprocal influence between opponents, if the intended outcome is to generalize and to provide advice for athletes and coaches [6,14,21]. According to Araújo et al. [14,27], the relative positioning of an attacker with the ball and an immediate opponent near an im- portant target area, (e.g. the goal/try line) typifies many $1 \mathrm{v} 1$ sub-phases of team sports, modeled as dyadic systems. Trying to capture the "ecological dynamics" of the penalty kick, implies at least two main conditions: i) that the experimental design be set up in the penalty area of an association football field (which can be faithfully simulated in a laboratory); and ii), that both players of the dyad are included in the design (i.e. penalty taker and goalkeeper). This approach ensures that the most important task constraints such as boundaries, markings, equipment and dyadic members are all included in the design characteristics of the experiment.

Ecological dynamics emphasizes the importance of identifying potential control parameters (variables that move a system into different states of organisation) at an ecological scale, and order parameters or collective variables that describe the state of a system. To achieve this aim experimental designs could include (i) task constraints (some of which have already been discussed) as well as others like the strategies of the goalkeeper, (e.g. mobility or immobility) during the run up, on- and off-center initial position; (ii) organismic constraints, like the influence of negative thoughts, induced or self-imposed instructions directed to avoid or engage in specific patterns of behavior, stress induction (e.g. through the creation of a penalty kicks ranking that generates an increase in player stress level), in order to analyze decision-making behavior of both players in the dyadic system. Decision making behavior could be observed by analyzing a 
number of key variables including, for example, the angle of approach to the ball by the penalty taker, or goalkeeper's lateral displacement over the goal-line during the run up. These designs may offer more valid descriptions and explanations for the kicker's choice for the ball's direction (height and side), and goalkeeper's choice for diving side.

As an example, we may consider the experimental design of Masters et al. [3], which tested the influence that imperceptible off-center positioning of goalkeepers exerted on kick direction of penalty shots. Their design characteristics suggested the need to include as participants, both goalkeepers and penalty takers; the research design involved the manipulation of information constraints (e.g, the perception of a goal's area) by repositioning of goalkeepers, with free performance of both players; finally in a laboratory test the following features could be included i) the calibration of the penalty kick area of an association football field, ii) the recording of penalty kick performances, iii) recording of the goalkeepers' initial positions relative to the center of the goal: e.g., $6-9 \mathrm{~cm}$ to left, $6-9 \mathrm{~cm}$ to right, on center (ex: footmarks on the goal-line). This approach allowed, for example, the influence of the goalkeeper's imperceptible displacement on kick direction to be assessed. The intention to capture the candidate variables that explain the interacting contribution of each player to the dyad is founded on the establishment of a relation between key variables (e.g. like angle, speed and acceleration of run up plotted against the lateral displacement of the goalkeeper) and observed performance outcomes. For example, a candidate order parameter could be the running correlation between the angle of the kicker's run up with the lateral displacement of the goalkeeper, and a candidate control parameter the goalkeeper's initial positions relative to the centre of the goal.

In applications to training design (outlined in Fig. 1), some basic ideas could be considered. Particularly in practice sessions before cup games which might be resolved through penalty kicks, coaches should enhance perceptual-motor training of this particular aspect of the game, involving all participants and encouraging the development of specific styles of penalty taking in individual players. Obviously, penalty kicking might be practised fairly regularly, but special attention is needed before cup games when a shoot out may occur because a larger number of players will typically be involved. These games are rare in the competitive playing schedule. Figure 1 presents potential aspects for the design and control of the practice tasks involving penalty kicks. The main principles supporting training of goalkeepers and penalty takers are: (i) to disguise his/her intention while trying to capture relevant information from the opponent's actions to anticipate his/her intentions; (ii) to be attuned to the specifying informational variables on the penalty kick, despite the presence of a large amount of irrelevant variables; (iii) to accept emotional variations as an integral and nonextractable part of penalty kick, for which on-field practice is the most representative solution. All these principles should be achieved with the support of statistical performance data from performance outcomes of team mates and opponents.

From the perspective of training program design, a sound methodology could be (i) to establish a goal that should be improved in penalty kick practice sessions; (ii) to define the relevant constraints that need to be manipulated in order to channel practice behavior in achieving that goal; and (iii) to create an exercise that integrates those constraints in a representative practice task. In this line of thought, we could include: (i) as an exercise goal: "to improve goalkeepers and penalty takers pressure tolerance, while facing opponents with differing kick strategies"; (ii) task constraints (players' strategies) and organismic constraints (e.g., pressure imposed by a shoot-out phase, rankings of success for all players); (iii) instructions during practice for goalkeepers to 1) move across the goal-line, 2) to remain still as late as possible or 3) to establish an initial position slightly to the left or right of center, and then try to save the penalty; for kickers 1) to take different angles of approach (with ground marks on a run-up area), 2) to take longer and shorter approaches, 3) to kick with right and left foot. A performance grid could be established for all players, with performance evaluation scores recorded, such as: (i) for kickers: 8 or more successes in 10 trials is defined as very good, 6 to 8 -medium, 6 or less-insufficient; (ii) for goalkeepers: 3 or more saves out of 10 is defined as very good, 2 in 10-medium, 1 or none-insufficient.

\section{CONCLUSIONS}

To conclude, the aims of this paper were (i) to overview the main findings from the key studies of the penalty kick in association football, and to comment on their representativeness of their experimental designs; (ii) to discuss the penalty kick performance context from an ecological dynamics viewpoint, explaining the complexity of decision-making behavior resulting from the interaction between penalty takers and goalkeepers.

In the penalty kick, the investigation of the goalkeeper's behavior can be explained by capturing key variables intrinsic to the dyad formed with each specific penalty taker under several types of constraints. A dyadic system is not equivalent to the summation of each individual's actions and an ecological dynamics approach provides principles and tools to study the emergent synergy between players in the penalty kick context. This perspective can allow analysis of the circular causality of each individual's (keeper and kicker) impact on his/her opponent, while all the actions of the system are influenced by previous, current and final states of that system. The most important aspect of this approach is that it uses dynamic measures that are based on the co-dependence of each individual involved in the context. This coupling could be reflected in key performance measurements, such as the running correlation between the angle of the kicker's run up with the lateral displacement of the goalkeeper, present in the time series of each individual's movements. Indeed, this measurement approach may be a way to quantify the "degree of connectedness" between social agents [25], such as the goalkeeper and penalty taker in the performance of the penalty kick in association football.

\section{REFERENCES}

[1] McGarry T, Franks I. On winning the penalty shoot-out in soccer. J Sports Sci 2000; 18: 401-9.

[2] Jordet G, Hartman E, Visscher C, Koen, AP. Kicks from the penalty mark in soccer: The roles of stress, skill, and fatigue for kick outcomes. J Sports Sci 2007; 25: 121-9. 
[3] Masters RSW, Van der Kamp J, Jackson RC. Imperceptibly offcenter goalkeepers influence penalty-kick direction in soccer. Psychol Sci 2007; 18(3): 222-3.

[4] Savelsbergh GJP, Van der Kamp J, Williams AM, Ward P. Anticipation and visual search behavior in expert soccer goalkeepers. Ergonomics 2005; 48(11-14): 1686-97.

[5] Van der Kamp J. A field simulation study of the effectiveness of penalty kick strategies in soccer: Late alterations of kick direction increase errors and reduce accuracy. J Sports Sci 2006; 24(5): 46777.

[6] Savelsbergh GJP, Williams AM, Van der Kamp J, Ward P. Visual search, anticipation and expertise in soccer goalkeepers. J Sports Sci 2002; 20: 279-87.

[7] Tyldesley DA, Bootsma RJ, Bomhoff GT. Skill level and eye movement patterns in a sport oriented reaction time task. In: Rieder H, Bos K, Mechling H, Reischle K, Eds. Proceedings of an International Symposium on Motor Behaviour: Contribution to Learning in Sport; Cologne: Hofmann; 1982; pp. 290-6.

[8] Reilly T, Clarys J, Stibbe A, Eds. Advance cue utilization in soccer. In: Science and Football II London: E \& FN Spon; 1993; pp. 23943.

[9] McMorris T, Colenso S. Anticipation of professional soccer goalkeepers when facing right- and left-footed penalty kicks. Percep Motor Skills 1996; 82: 931-4.

[10] Morya E, Ranvaud R, Pinheiro WM. Dynamics of visual feedback in a laboratory simulation of a penalty kick. J Sports Sci 2003; 21: 87-95.

[11] Van der Kamp J, Masters RSW. The human Müller-Lyer illusion in goalkeeping, perception (in press).

[12] Bakker FC, Oudejans RD, Binsch O, Van der Kamp J. Penalty shooting and gaze behavior: Unwanted effects of the wish not to miss. Int J Sport Psychol 2007; 37: 265-80.

[13] Morris A, Burwitz L. Anticipation and movement strategies in elite soccer goalkeepers at penalty kicks. J Sports Sci 1989; 7: 79-80.

[14] Araújo D, Davids K, Hristovski R. The ecological dynamics of decision making in sport. Psychol Sport Exerc 2006; 7: 653-76.
[15] Davids K, Button C, Araújo D, Renshaw I, Hristovski R. Movement models from sports provide representative task constraints for studying adaptive behavior in human movement systems. Adapt Behav 2006; 14(1): 73-95.

[16] Passos P, Araújo D, Davids K. Information governing dynamics of attacker-defender interactions in youth rugby union. J Sport Sci (in press).

[17] Araújo D, Davids K, Passos P. Ecological validity, representative design, and correspondence between experimental task constraints and behavioral setting: comment on Rogers, Kadar, and Costall (2005). Eco Psychol 2007; 19(1): 69-78.

[18] Brunswik E. Perception and the representative design of psychological experiments. Berkeley: University of California Press 1956.

[19] Gibson J. The ecological approach to visual perception. Boston: Houghton Mifflin 1979.

[20] McGarry T, Anderson DI, Wallace SA, Hughes MD, Franks IM. Sport competition as a dynamical self-organizing system. J Sports Sci 2002; 20: 771-81.

[21] Reilly T, Cabri J, Araújo D, Eds. Applications of dynamical systems theory to football. Science and football V; London: Routledge; 2005; pp. 547-60.

[22] Handford C, Davids K, Bennett S, Button C. Skill acquisition in sport: Some applications of an evolving practice ecology. J Sports Sci 1997; 15: 621-40.

[23] Warren WH. The Dynamics of Perception and Action. Psychol Rev 2006; 113(2): 358-89.

[24] Montagne G. Prospective control in sport. Int J Sport Psychol 2005; 36: $127-50$

[25] Marsh KL, Richardson MJ, Baron RM. Contrasting approaches to perceiving and acting with others. Eco Psychol 2006; 18(1): 1-38.

[26] Davids K, Button C, Bennett SJ. Dynamics of skill acquisition: A constraints-led approach. Champaign, Ill.: Human kinetics 2008.

[27] Williams AM, Hodges NJ, Eds. Emergence of sport skills under constraints. Skill acquisition in sport: Research, theory and practice, London: Routledge 2004; pp. 409-33.

Received: March 26, 2008

Revised: April 23, 2008

Accepted: May 5, 2008

(C) Lopes et al.; Licensee Bentham Open.

This is an open access article distributed under the terms of the Creative Commons Attribution License (http://creativecommons.org/licenses/by/2.5/), which permits unrestrictive use, distribution, and reproduction in any medium, provided the original work is properly cited. 